\title{
THE 4DCAD IN PROJECT PLANNING AND BUDGETING OF THE NEW URBAN INFRASTRUCTURE FOR THE PHITSANULOK CENTRAL PARK, THAILAND
}

\author{
Kumpon SUBSOMBOON ${ }^{1}$, Boonsong TANTANEE ${ }^{2}$, Suchanya SARATAI, \\ PANU BURANAJARUKORN ${ }^{4}$
}

DOI: 10.21163/GT_2019.141.18

\begin{abstract}
:
The research aim is to develop the 3DCAD and 4DCAD models, based on BIM technology, for project planning and budgeting of the new urban infrastructures of the Phitsanulok Central Park in Thailand to achieve the goal of establishment of "Phitsanulok Green and Healthy City". This newly project was proposed by the Phitsanulok City Municipality and designed by Naresuan University team. The traditional 2D drawing format and specifications were delivered for procurement process. Then 3DCAD model was developed based on 2D drawings with Microstation based software. The 15 months original construction schedule was developed as an initial plan with the 120 million Baht estimated cost. Moreover, 4DCAD model was developed with the AECO Sim Building Designer, a linkage of simulation model between 3DCAD model and construction schedule, to simulate the what-if scenario of the proposed construction plan. According to limitation of government's budget, project allocation of financial budget became an important constraint. Therefore, the initial plan was revised into the phases based on the approved and proposed budgets for the future to complete the project as an alternative schedule. Finally, the related 4DCAD models were developed in order to satisfy the project participants and improved the project more understandable.
\end{abstract}

Key-words: 4DCAD, Building Information Modeling (BIM), Project Planning and Budgeting, Urban Infrastructure.

\section{INTRODUCTION}

Since 2012, the Phitsanulok City Municipality has been working with Naresuan University (NU) for researching and designing a newly proposed central park's infrastructure with an estimated 120 million Bath budget to flip the area in the heart of the city from an overcrowded existing area of the police station headquarter to a newly proposed central park in order to be the Phitsanulok green and healthy city. The development of infrastructure would improve the sustainability of productive areas (Turon \& Gomis, 2016). However major constraints of the project, mainly financial and physical constraints, affect the project's plan. The expected difficulties have been realized by the

1 Naresuan University, Center of Excellence on Energy Technology and Environment, and Department of Civil Engineering, Faculty of Engineering, Thailand, kumpon@nu.ac.th;

2 Phitsanulok City Municipality, Mayor, Phitsanulok, Thailand, mayor@phsmun.go.th;

3 Naresuan University, Department of Civil Engineering, Faculty of Engineering, Thailand, suchanya.saratai@gmail.com;

4 Naresuan University, Center of Excellence on Energy Technology and Environment, Faculty of Engineering, Thailand,dr.panoo.boo@gmail.com. 
Municipality since the design phase from the project constrains. From this reason, the Phitsanulok City Municipality need to communicate with the project stakeholders, especially government officers, police officers, and people living in the municipality area showing benefits and effects of the project during the pre-construction and construction phase. Since the project understanding is one of the key issues for the project success especially government budget approval process, the Phitsanulok City Municipality and NU design team is looking for a new technique in engineering and design process to communicate a program planning of the proposed project to the project participants.

With the innovation of digital technologies in design and construction, Architectural, Engineering, and Construction (AEC) agencies are transitioning from two-dimensional (2D) paper-based to three-dimensional (3D) digital data-based project delivery. In recent years, three-dimensional/four-dimensional computer aided design (3D/4D CAD) models based on the Building Information Modeling (BIM) were increasingly used in design and construction projects. This BIM model includes graphics data, geometric data, and its associated databases. The 3D/4D models have been investigated to improve construction related activities over the years in order to support management tasks such as visualization, planning, coordinating, and construction safety (Hartmann et al., 2008).

The adoption of these technologies and tools can generally improve construction related tasks such as safety, quality, productivity, constructability, error detection, and communication of projects. The 4D models could be a beneficial alternative to construction project scheduling tools such as Critical Path Method (CPM) networks and bar charts. In addition, the potential of $\mathrm{BIM}$ based 3D/4D technologies have been accepted by practitioners. However, these technologies have not widely been implementing especially in public sector in Thailand. Therefore, the aim of this research is to develop and apply the 3DCAD and 4DCAD models, based on BIM technology, for project planning and budgeting of the new urban infrastructures of the Phitsanulok Central Park in Thailand.

\section{BIM/3DCAD/4DCAD APPLICATIONS ON URBAN INFRASTRUCTURE}

\subsection{BIM/3DCAD/4DCAD Applications}

Schedule delay and cost overrun were usually caused by insufficient communication among project participants in traditionally executed infrastructure projects (Guo et al., 2017). The 2D paper-based drawings and hard copy documents required extra time investment to be shared physically within AEC agencies and between project participants, which prohibits real-time and effective communications. BIM technology enables the design with a precise digital virtual model. It supports integrating all stakeholders' mission on a project, visualizing building structure in a simulated environment, and identifying any potential problematic issues in design, construction, or operation (Azhar, 2011).

BIM model can be applied through the project life cycle: planning, design, construction, operation, and maintenance of the facility. It makes a valuable change in the workflow and project delivery process by using 3D intelligent models. Precise geometry and relevant data of the BIM objects for example spatial relationships, geometry, geographic information, quantities, properties of building elements, material inventories, construction schedule, and cost estimates data are included in a BIM model to support the design, procurement, fabrication, and construction activities (Eastman et al., 2011). After completion of the construction phase, the model can be used for operations and maintenance purposes. Its related advantages are as follows: faster and more effective processes, better design and better production quality, controlled whole-life costs and 
environmental data, automated assembly, better customer service and lifecycle data (Azhar, 2011; Eastman et al., 2011). Areas of application for BIM models include visualization, virtual design reviews, interference detection, analyzing design options, cost estimate, construction document production, fabrication, construction sequencing (Hartmann et al., 2008). Project team can use BIM models for marketing purpose or communicate to the society on projects. Photorealistic computer renderings, 3D walk through, and movie clips can be created and showed to project stakeholders for better communication and visualization (Hartmann et al., 2008). Designers and contractors can use BIM models to improve the traditional 2D drawings limitation in complicated issues. Both architects and engineers in different locations can concurrently review designs via the Internet. Engineers can use BIM models as input for design software for analyzing design options resulting in more accurate results. A Bill of Quantities (BOQ) can be directly generated from BIM model for cost estimate. BIM models can make better design resulting in better construction documents. Project managers can use 4DCAD models that link 3DCAD models to analyze construction operations together with construction schedules, and then simulate alternative construction scenarios based on their schedules (Koo \& Fischer, 2000).

The outcome of 4DCAD models are in marketing, schedule development, schedule/sequence visualization, coordination, communicating to city officials, conflict resolution, and owner updates (Hastings et al., 2003). Related 4D CAD research has been developing in the BIM related construction research community. For example, 4D CAD system can be used to support analysis of the 4D objects for horizontal elements including a visual simulation of a cutting and filling status of an earth work section in civil engineering projects (Kang et al., 2013). The 4D simulation is the most widely used product resulting in improving project communication (Dang \& Bargstadt, 2015). Contractors can improve their planning and crew productivity by using automated productivity-based schedule animation with BIM in 4D environment (Gelisen \& Griffis, 2014). Currently, 4D model for constructability reviews is also one of the most common tool used in construction industry (Kifokeris \& Xenidis, 2017).

\subsection{A case study: Phitsanulok Central Park}

To achieve the goal of establishment of "Phitsanulok Green and Healthy City", this newly project was proposed by the Phitsanulok City Municipality and designed by NU team based on the universal design concept. The traditional two-dimensional (2D) drawing format and specifications were delivered as one of the requirements for procurement process. A newly proposed central park's infrastructure with an estimated budget of 120 million Baht comprises of park, pavilion, outdoor stage, fountain, playground, garage building, bike station, footpath, and systems for sanitary, pumping, lighting and electricity, and demolition works of the existing police station buildings. However the major constraints that are mainly financial and physical constraints, still affect the project plan. The expected difficulties have been realized by the Municipality since design and preconstruction phase from the project constrains. The project location was a physical constraint because of it has been used as a police station headquarters. The police station was expected to move to a new building nearby, however the construction of the new headquarter had been delayed since the contractor could not finished the construction project on time. Initially, the governor approved some budget for relocating and constructing the new sewer system and footpath for the project, however the budget was on held because of the delay. From this reason, financial budget has become a critical factor requiring the understanding from the government to support and provide the budget for the 
project in the future. Therefore, the Phitsanulok City Municipality need to communicate with the project stakeholders showing benefits and effects of the project during the preconstruction and construction phase. Since the project understanding is one of the key issues for the project success especially government budget approval process, the Phitsanulok City Municipality and NU design team is developing and implementing the $3 \mathrm{D} / 4 \mathrm{D}$ technology in project planning and budgeting to communicate a program planning of the proposed project to the project stakeholders based on approved and proposed budget.

\section{METHODOLOGY}

The procurement process of this project required 2D drawings and specifications as one of the products in traditional project delivery system. The NU engineering team developed a 3D/4 D model as an extra package in order to investigate and research the development and implementation of the 3D/4D technology on design and construction process. In addition, the $3 \mathrm{D} / 4 \mathrm{D}$ model was used as a visualization tool presenting to the stakeholders for communication purpose. The 3D model, representing 3D BIM objects relevant to the $\mathrm{x}, \mathrm{y}, \mathrm{z}$ Cartesian coordinate system, was developed by using the AECO Sim Building Designer from Microstation. The approved data and information from 2D drawings (plan data in xy plane, section data in yz plane and xz plane) and specifications (e.g. material properties) in traditional design process were used as basis information. The schedule of the project was developed with Primavera's P3 scheduling software. The AECO Sim Building Designer was also used as a 4D simulation application. It imported the schedule (represent time attribute) and BIM based data and allowed users to link the activities with their related objects or components. The resulting 4D model presented the construction sequences by showing consecutive 3D BIM objects as time progresses. The main purpose of this 4D application was to simulate the sequential scenario of the proposed construction plan based on their different construction schedules. The original schedule could be linked with the 3D objects to simulate the original 4D model. In case of the original schedule was affected from the financial constraint (e.g. approved budget from the government). The revised schedule was needed to be reconsidered for example extending schedule into a yearly basis. The revised schedule could be also considered the proposed budget from the government in the future until the completion of the project respectively.

\section{RESULTS AND DISCUSSIONS}

The 15 months original schedule comprising of 59 activities was initially developed for completion the project using Primavera's P3 scheduling software (Fig. 1). However, the schedule can be done by using Microsoft Project software or AECO Sim which allow users to create their schedules in the AECO Sim. A graduate student who experienced in BIM software developed the 3D model by using AECO Sim Building Designer. It took approximately 45 days for developing the 3DCAD, 2 days for scheduling, and 2 days for 4D analyses. The total work-day was approximately 49 days. Fig. 2 illustrates the 3DCAD of the new urban infrastructure of the Phitsanulok Central Park with the name of graphic group that more convenient to link with the activities. Fig. 3 presents the linking process between 3D objects (graphic group) and activities. 


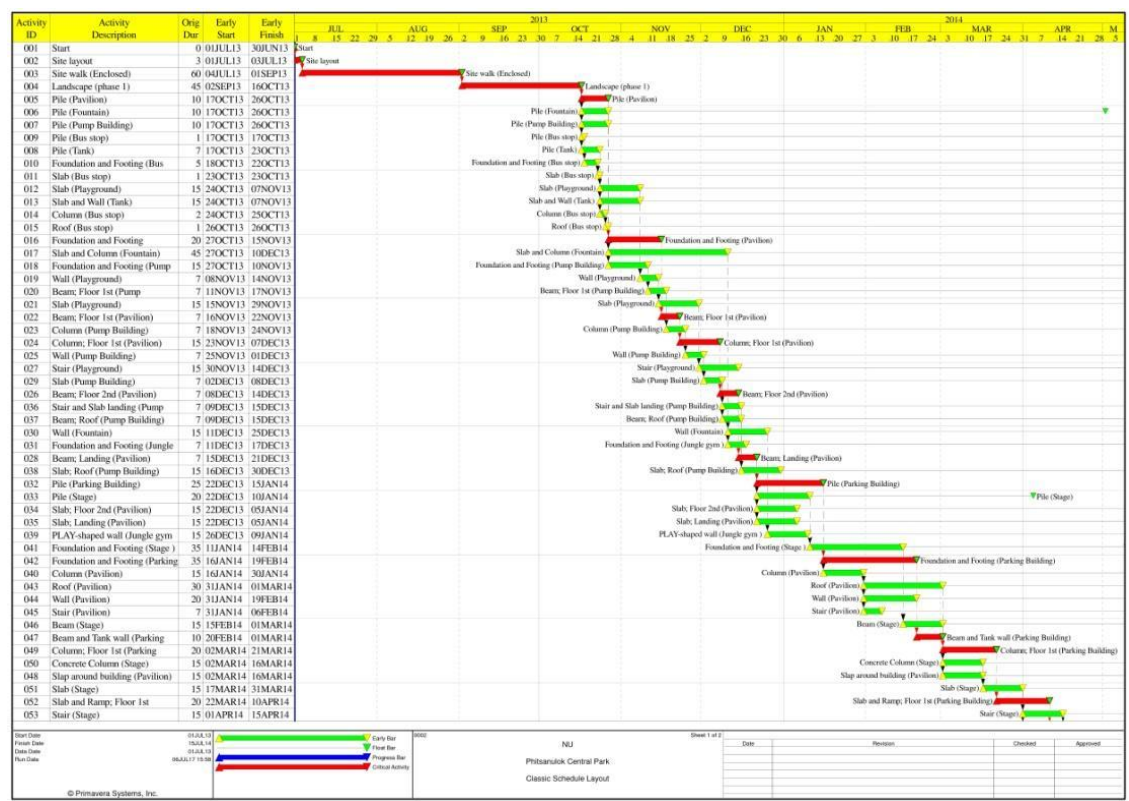

Fig. 1. Original schedule of the Phitsanulok Central Park.

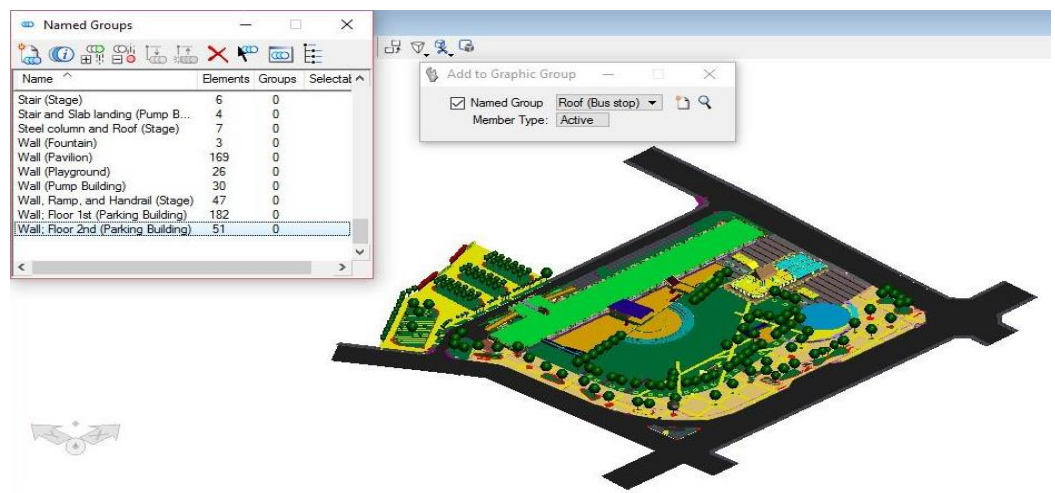

Fig. 2. 3DCAD of the Phitsanulok Central Park with the graphic group's name.

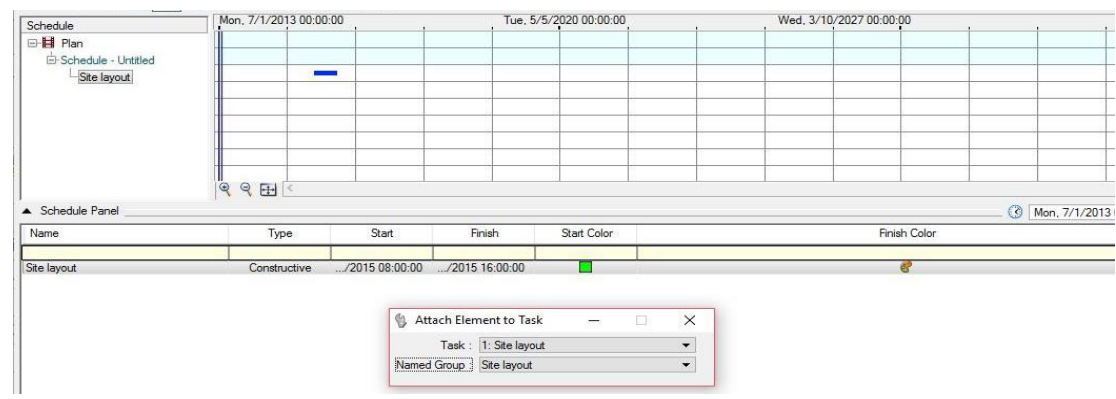

Fig. 3. Linking 3D objects to activities. 


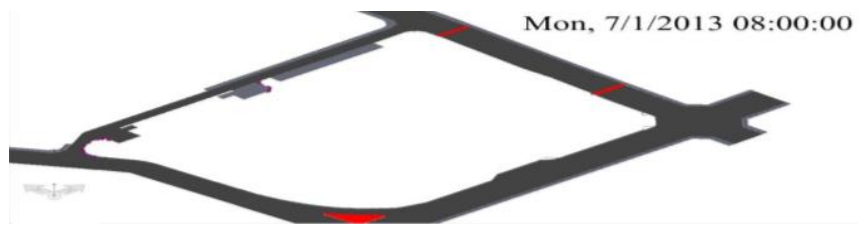

4a) 4DCAD of the Phitsanulok Central Park based on the original schedule on July 2013

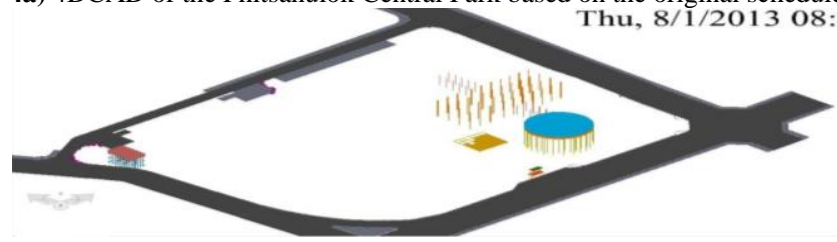

4b) 4DCAD of the Phitsanulok Central Park based on the original schedule on August 2013

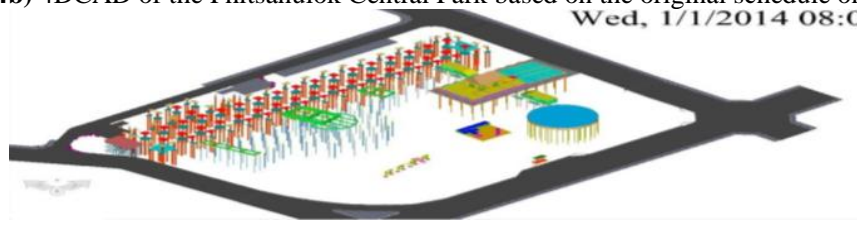

4c) 4DCAD of the Phitsanulok Central Park based on the original schedule on January 2014

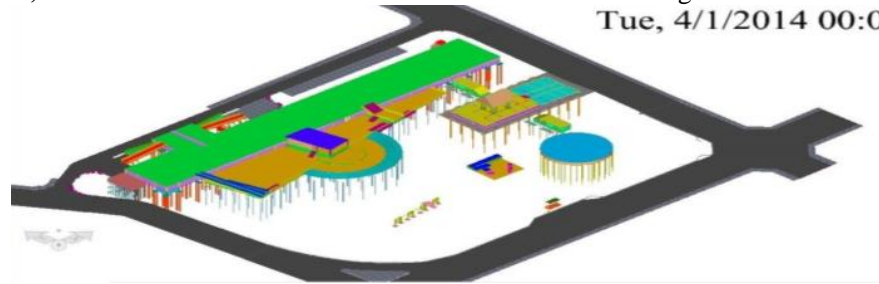

4d) 4DCAD of the Phitsanulok Central Park based on the original Schedule on April 2014.

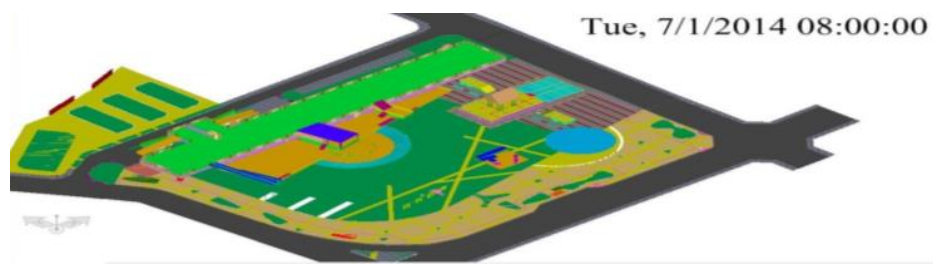

4e) 4DCAD of the Phitsanulok Central Park Based on the Original Schedule on July 2014.

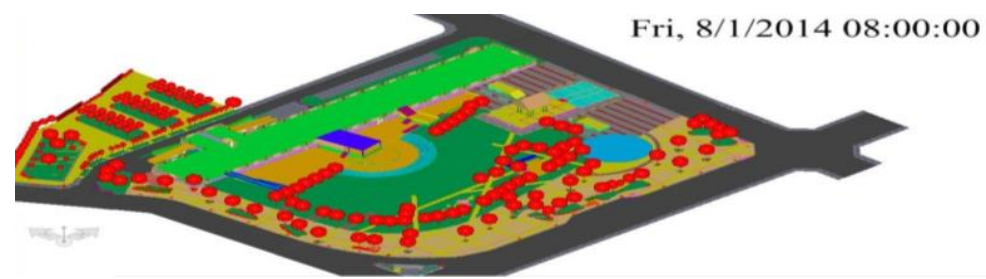

4f) 4DCAD of the Phitsanulok Central Park based on the original schedule on August 2014 .

Fig. 4. 4DCAD of the Phitsanulok Central Park Based on the Original Schedule. 
The original 4D model illustrates construction sequences by showing consecutive 3D objects within 15 months of project duration in Fig. 4. Fig. 4a-4f show the 4DCAD of the construction project based on the original schedule on July 2013, August 2013, January 2014, April 2014, July 2014, and August 2014, respectively. According to obstacles of the physical and financial constraints, the original project schedule had been delayed. Therefore, the revised schedule was developed based on the approved budget resulting from the constraints as a new alternative schedule.

Fig. 5 illustrates the concept of the revised schedule on yearly basis which modified from the original schedule by changing date. The revised schedule has been proposed in to four phases including 1) year 2014-2015 2) year 2016-2017 3) year 2018-2019 and 4) year 2020-2021.

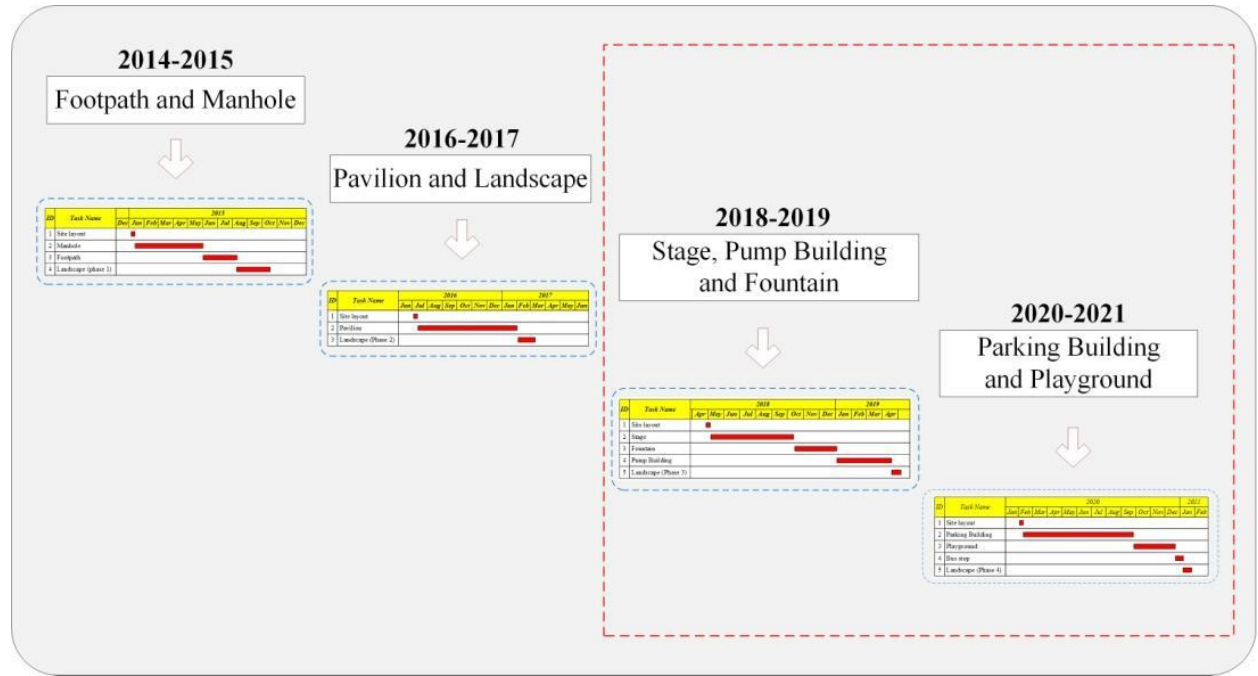

Fig. 5. Concept of the Revised Schedule of the Phitsanulok Central Park Based on Financial Constraint.

Finally, the revised 4DCAD based on alternative schedule displays the construction sequences on yearly basis resulting from the approved budget from the government as well as the proposed budget in the future (Fig. 6). Fig. 6a-6d show the 4DCAD of the construction project based on the revised schedule on December 2015, 2017, 2018, and 2021, respectively. After completely developing the revised 4DCAD, it was presented to the Phitsanulok City Municipality's committee including mayor, municipality clerk, division directors, engineers, architects etc.

The 3D/4D models were used during pre-construction and construction phase. The benefits of 4D models were evaluated and shown their improvements in communicating to a governor and people in municipality area, marketing, coordination, schedule development, schedule/sequence visualization, conflict resolution, constructability review, and owner updates (Hartmann et al., 2008; Azhar, 2011; Eastman et al., 2011; Koo and Fischer, 2000; Hastings et al., 2003). As of March 2018, the construction of the first and second phases was completed based on their budgets. The third phase of the project is an on-going construction process. The Municipality is expected to get funding of the fourth phases of the project in 2020 . 


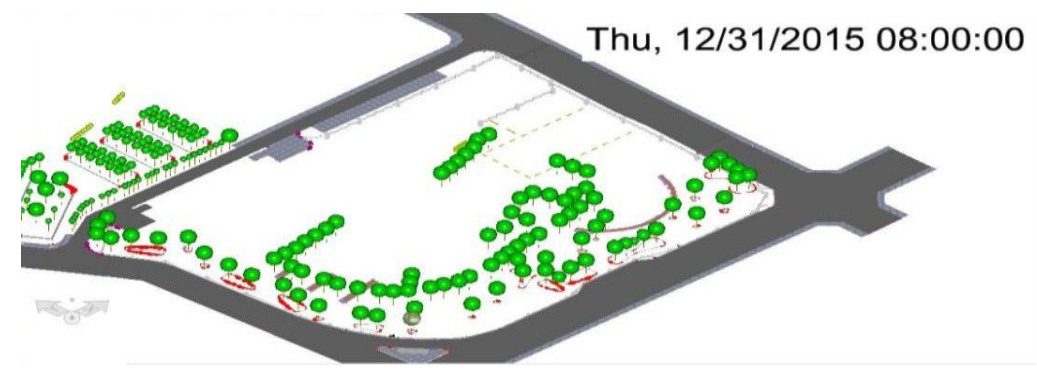

6a) 4DCAD of the Phitsanulok Central Park Based on the Revised Schedule on December 2015.

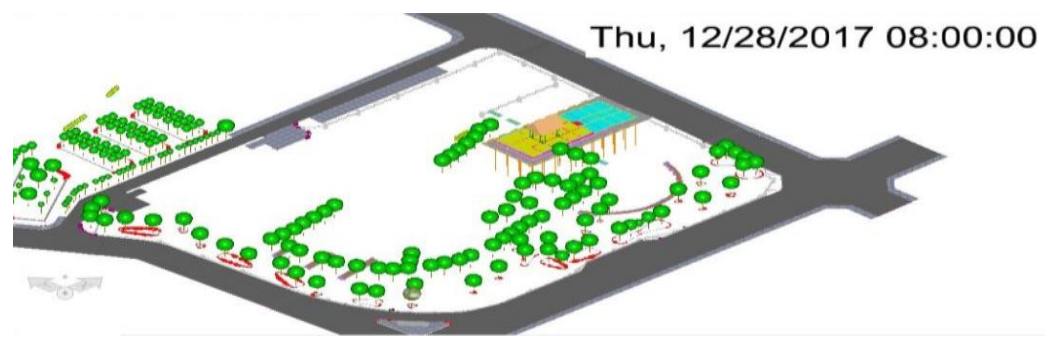

6b) 4DCAD of the Phitsanulok Central Park Based on the Revised Schedule on December 2017

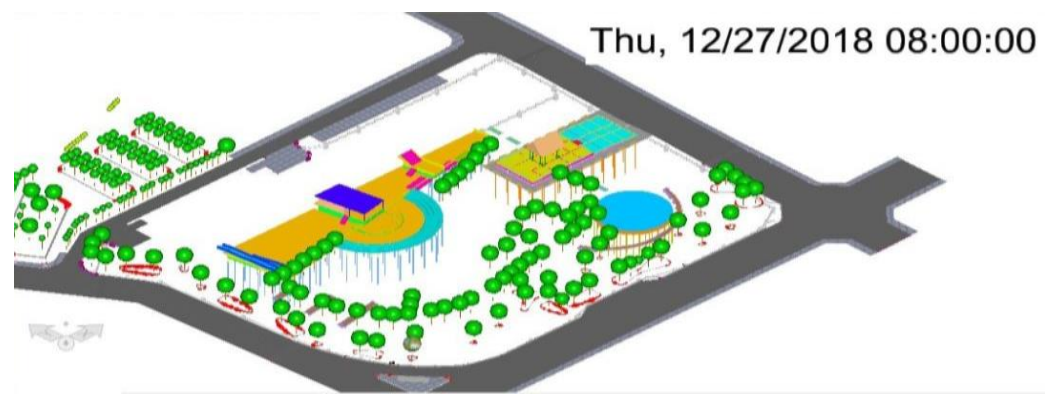

6c) 4DCAD of the Phitsanulok Central Park Based on the Revised Schedule on December 2018

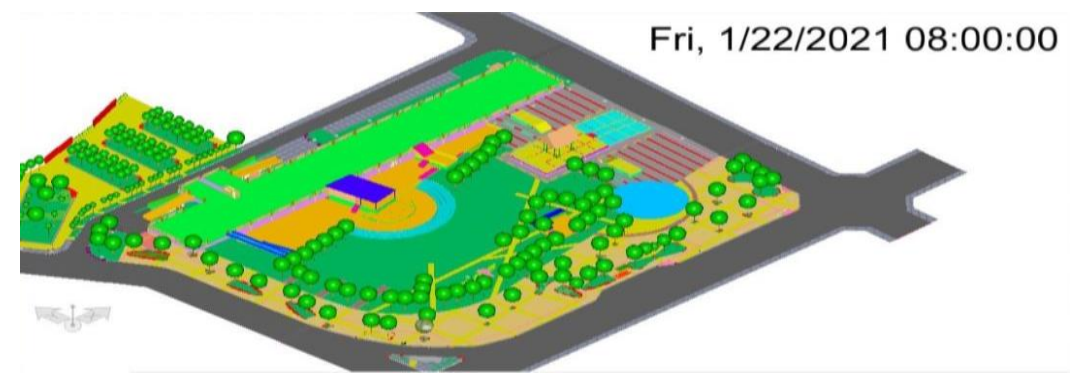

6d) 4DCAD of the Phitsanulok Central Park Based on the Revised Schedule on December 2021

Fig. 6. 4DCAD of the Phitsanulok Central Park Based on the Revised Schedule 


\section{CONCLUSIONS}

This research developed and applied 3D/4D CAD models based on BIM technology for project planning and budgeting of the new urban infrastructures of the Phitsanulok Central Park in Thailand. The 3D/4D models were developed using AECO Sim Building Designer. The first version of 4D model was developed based on the 15 months original construction schedule with the 120 million Bath estimated cost. The second version of 4D model was developed based on the revised construction schedule according to the approved government budget, and proposed budget. The 4D models simulate the what-if scenario based on their construction schedules. The benefits of 4D models of the new urban infrastructures of the Phitsanulok Central Park were evaluated and shown their improvements in communicating to people in municipality area, coordination, marketing, schedule development, schedule/sequence visualization, communicating to a governor, conflict resolution, constructability review and owner updates. The project participants have satisfied with the use of 3D/4D models and their benefits which improved the project more understandable.

\section{ACKNOWLEDGEMENTS}

The authors wish to express their gratitude to the Phitsanulok City Municipality for their support on the project.

\section{REFERENCES}

Azhar, S. (2011) Building Information Modeling (BIM): Trends, Benefits, Risks, and Challenges for the AEC Industry. ASCE Leadership and Management in Engineering, 11 (3), 241-252.

Dang, T. and Bargstadt, H. (2015) 4D Relationships: The Missing Link in 4D Scheduling. ASCE Journal of Construction Engineering and Management, 142 (2), 04015072-16.

Eastman, C., Teicholz, P., Sacks, R. \& Liston, K. (2011) BIM Handbook: A Guide to Building Information Modeling for Owners, Managers, Designers, Engineers and Contractors, 2nd Edition, John Wiley \& Sons, Hoboken, New Jersey, USA.

Gelisen, G. \& Griffis, F. H. (2014) Automated Productivity-Based Schedule Animation: SimulationBased Approach to Time-Cost Trade-Off Analysis. ASCE Journal of Construction Engineering and Management, 140 (4), B4013007-10.

Guo, F., Jahren, C.T., Turkan, Y. \& Jeong, H. D. (2017) Civil Integrated Management: An Emerging Paradigm for Civil Infrastructure Project Delivery and Management, ASCE Journal of Management in Engineering, 33 (2), 04016044-10.

Hartmann, T., Gao, J. \& Fischer, M. (2008) Areas of Application for 3D and 4D Models on Construction Projects. ASCE Journal of Construction Engineering and Management, 134 (10), 776-785.

Hastings, J., Kibiloski, J., Fischer, M., Haymaker, J. and Liston, K. (2003) Four-Dimensional Modelling to Support Construction Planning of the Stata Center Project, ASCE Leadership and Management in Engineering, 3(2), 86-90.

Kang. L., Pyeon, J., Moon, H., Kim, C. \& Kang, M. (2013) Development of Improved 4D CAD System for Horizontal Works in Civil Engineering Projects. ASCE Journal of Computing in Civil Engineering, 27(3):212-230.

Kifokeris, D. and Xenidis, Y. (2017). Constructability: outline of past, present, and future research. ASCE Journal of Construction Engineering and Management, 143 (8), 04017035-13.

Koo, B. \& Fischer, M. (2000) Feasibility of 4D CAD in commercial construction. ASCE Journal of Construction Engineering and Management, 126(4), 251-260.

Turon, C. \& Gomis, J. (2016) Implementation of Elements of Sustainability Applied to the Urbanization of Productive Areas. Geographia Technica, 11 (2), 113-124. 